\title{
EDUARDo LOURENÇO E A ATEMPORALIDADE DE EçA DE Queirós
}

\section{Eduardo Lourenço and timeless Eça de Queirós}

\author{
Antonio Augusto Nery
}

\begin{abstract}
RESUMO
Eduardo Lourenço, em seu artigo crítico "O tempo de Eça e Eça e o tempo", propõe que os vínculos entre a ficção eciana e a realidade Oitocentista ultrapassam o contexto histórico do século XIX e refletem, de maneira avultante, nossa condição contemporânea. Para o crítico, "Tudo quanto caracteriza hoje, noutro ritmo e com outra potência, a nossa actual civilização, já é visível e está presente no tempo em que o autor de Os maias viveu, constituindo o pano de fundo da sua experiência vital e cultural" (LOURENÇO, 2006, p. 35). Para tecer suas considerações sobre o modo como Eça de Queirós dialogava com as transformações de várias ordens que ocorriam no século XIX, Lourenço detém-se especialmente sobre os textos ficcionais produzidos pelo escritor. O objetivo deste trabalho é averiguar em que medida as proposições de Eduardo Lourenço podem ser transpostas para as produções de Eça em outros gêneros textuais, tais como crônicas e artigos jornalísticos. Para tanto, me deterei especificamente na análise dos textos escritos por Eça para os panfletos As farpas, entre 1871 e 1872, e alguns artigos publicados pelo escritor em jornais, durante a década de 1890 .

Palavras-chave: Eça de Queirós; Eduardo Lourenço; literatura e realidade.
\end{abstract}




\begin{abstract}
Eduardo Lourenço, in his article "O tempo de Eça e Eça e o tempo", affirms that the connections between the fiction of Eça de Queirós and the nineteenth-century reality are more than just the historical context of the XIX century, because reflect, in a degrading way, our contemporary condition. For the critic, "Everything that characterizes today, in another rhythm and with other power, our existing civilization, is already visible and present at the time in which Os maias' author lived, constituting the background of his vital and cultural experience" (LOURENÇO, 2006, p. 35). To understand how Eça de Queirós dialogued with the changes that were taking place during the XIX century, Lourenço analyses the fictional texts produced by the author. The goal of this article is to check the possibility of applying Eduardo Lourenço's propositions to other textual genders that Eça produced, such as chronic and newspaper articles. In order to do so, I will analyze the texts that Eça produced for As farpas, between 1871 and 1872, and some articles published by the author for newspapers during the 1890's.
\end{abstract}

Keywords: Eça de Queirós; Eduardo Lourenço; literature and reality.

Tentar abarcar em poucas linhas todo o pensamento de Eduardo Lourenço (1923) sobre Eça de Queirós (1845-1900) soa um tanto quanto pretensioso, pois não foram poucas as vezes em que o crítico português dedicou-se, direta ou indiretamente, à obra de um dos maiores prosadores da Língua Portuguesa. Para o espaço que aqui disponho, selecionei um texto de Eduardo Lourenço sobre Eça que poucas vezes foi retomado pela crítica. Trata-se da reflexão "O tempo de Eça e Eça e o tempo", apresentada por Lourenço no Congresso Internacional dos "150 anos com Eça de Queirós", evento realizado entre os dias 18 a 21 de setembro de 1995, na Universidade de São Paulo. O artigo foi publicado na revista Convergência Lusíada, em 1996, e, posteriormente, republicado nos anais do Congresso onde fora apresentado, volume de 1997. Em 2006, o texto foi coligido no livro $A s$ saias de Elvira e outros ensaios, coletânea de textos de Eduardo Lourenço, publicada pela Editora Gradiva ${ }^{1}$.

1 O artigo também integra a coletânea de textos críticos sobre Eça de Queirós, Diálogos com Eça no Novo Milénio, organizada em 2004 por Ana Nascimento Piedade, Ana Isabel Vasconcelos e Alfredo Campos Matos, e publicada em Lisboa pela Editora Livros Horizonte. 
Em suas considerações, Eduardo Lourenço propõe que os vínculos entre a ficção queirosiana e a realidade Oitocentista ultrapassam o contexto histórico do século XIX e refletem, de maneira avultante, nossa condição contemporânea. Cito, de início, um trecho que poderia sintetizar as proposições formuladas por Lourenço:

Tudo quanto caracteriza hoje, noutro ritmo e com outra potência, a nossa actual civilização, já é visível e está presente no tempo em que o autor de Os maias viveu, constituindo o pano de fundo da sua experiência vital e cultural. Isso é sobretudo exacto para quem não viveu esse tempo como específico tempo português o que foi o caso de Eça - pois o nosso não era ainda o de uma "sociedade de massas" nem de revolução científica e só o foi lá fora, com propriedade, no fim do século, nas grandes metrópoles. (LOURENÇO, 2006, p.35-36)

A ideia de que o tempo de vivência fora de Portugal - ressalte-se que Eça de Queirós deixou o país em 1873 para seguir a carreira diplomática e nunca mais voltou a residir definitivamente na terra natal - oportunizou a Eça não somente analisar o país com algum distanciamento crítico, mas, sobretudo, vivenciar as benesses e as mazelas da Modernidade, que pôde usufruir em suas estadas como cônsul na Inglaterra e na França.

Por conta dessa condição "estrangeira", Eça seria aquele que, dentre todos os integrantes da Geração de 70, de maneira mais proeminente conseguiu se conectar às transformações de várias ordens que acometeram a sociedade européia durante o século XIX, especialmente na segunda metade:

No fim de sua vida, como espectador interessado e implicado nela [na sociedade de massas], o autor de $A$ cidade e as serras foi já contemporâneo dessa sociedade massificada que não era fenômeno quantitativo mas qualitativo pois alterou o estatuto dos indivíduos na sociedade e, em particular, o estatuto real ou simbólico de que os artistas e os intelectuais gozavam e de que os representantes da Geração de 70 são, entre nós, a mítica e quixotesca expressão. Mas só Eça foi realmente na vida e na imaginação, o habitante desse novo mundo (LOURENÇO, 2006, p. 36, itálicos do autor)

Para o crítico, além de Eça demonstrar insatisfação com o Portugal que tinha diante de si, também não se reconhecia ou não se adaptava passivamente às rápidas transformações do fin-de-siécle, à fluidez moderna, ou à "falta de solidez" da modernidade, para lembrarmos as acepções já consagradas por Marshal Berman (1989) e Zygmund Bauman (2001) para descrever o processo de modernização. 
De fato, Lourenço chama a atenção para uma faceta pouco explorada de Eça de Queirós, extravasando a alcunha tradicionalmente atribuída ao escritor, de "realista e crítico social". Como contemplador da emblemática segunda metade do século XIX, Eça traduziu em sua produção ficcional e não ficcional um contexto de mudanças que, além de instituir historicamente o Oitocentos como ponto de chegada, em termos de evoluções e revoluções, constituiu-o também como um contexto de crise. Tempo em que houve a superação de paradigmas e convicções e em que se conviveu com crises e tensões pautadas em pólos opostos, tais como conservação e ruptura, tradição e modernidade, individualidade e coletividade, urbano e rural, além de inúmeras outras dialéticas.

Dessa forma, na perspectiva de Eduardo Lourenço, para além de pontualmente compreendermos a obra de Eça como um "inquérito à vida burguesa", precisamos lê-la como representação ampla das características de um momento histórico que o historiador Erich Hobsbawn (2011, p. 20) denominou "longo século XIX", ao propor que os acontecimentos, crises e transformações do contexto oitocentista estabeleceram-no como um período singular da história da humanidade, resultando em significados e desdobramentos que continuam - e continuarão - atuando na constituição de nossa realidade atual.

É essa característica da obra queirosiana que recebe a atenção de Eduardo Lourenço no ensaio crítico em questão. Para o pensador, dentre todos os integrantes da Geração de 70, Eça de Queirós foi aquele que de maneira mais plena e eloquente captou em seus textos as novidades, mudanças, imposições e problemas que as transformações modernas traziam:

[...] só na obra de Eça, graças ao seu extraordinário mimetismo cosmopolita, nós temos a sensação de viver com ele e através dele $o$ tempo próprio da segunda metade do século. Século que não foi apenas o da mudança de ritmo na civilização material e de costumes exteriores mas sobretudo, um tempo que era ele mesmo nova visão de mundo, instalando-nos num presente que se dizia civilizado e moderno. Ou melhor, que se inventava como Modernidade. É nesse tempo novo que a obra de Eça de Queirós nos instala, de maneira sensível, com uma nitidez e uma familiaridade, por assim dizer, não só mágicas, mas propriamente míticas. A temporalidade única desse momento histórico vital, cultural, está impressa, infiltrada no tecido de sua ficção e alimenta como sangue escrito cada linha do seu texto. (LOURENÇO, 2006, p. 36, itálicos do autor)

Para a construção de sua argumentação, Lourenço dialoga quase que exclusivamente com os últimos textos ficcionais produzidos por Eça, 
especialmente as produções posteriores a Os maias - ou seja, de 1888 até a morte do escritor, em 1900.

Considerando isso, meu esforço neste trabalho será averiguar em que medida a "atemporalidade" da obra queirosiana, expressa por Eduardo Lourenço, pode ser transposta para as produções de Eça em outros gêneros textuais, tais como crônicas e artigos jornalísticos, produzidos em diferentes períodos da vida do escritor.

O primeiro texto a que me dedicarei é proveniente d'As farpas ${ }^{2}$, panfletos críticos publicados por Eça de Queirós em conjunto com Ramalho Ortigão (1836-1915). Eça participou ativamente das publicações entre 1871 e 1872; os textos de sua autoria foram revisados por ele próprio ${ }^{3}$ e coligidos, entre 1891 e 1892, no volume Uma campanha alegre ${ }^{4}$. O artigo que analisarei integra As farpas de março de 1872.

O segundo texto que receberá minha atenção é um dos artigos escritos por Eça para a Gazeta de Notícias do Rio de Janeiro, publicado em julho de 1893, e coligido postumamente na obra Notas contemporâneas, de 1909.

Iniciemos pelas Farpas...

De saída, esclareço que não mencionarei, durante a exposição, o quanto as assertivas de Eça poderiam ser naturalmente deslocadas para nossos dias. Creio que o apontamento é desnecessário porque a rua, os programas televisivos, as revistas, os jornais, a mídia em geral, são testemunhas óbvias da atualidade crítica de Eça, capaz de ser apreendida à medida que vamos lendo seus escritos.

Pois bem, neste artigo datado de março de 1872, o escritor se dedica a criticar a educação portuguesa, mais precisamente a educação dada às mulheres no país. Em certo momento da argumentação, Eça abre uma considerável digressão e passa a refletir sobre certa "ditadura da moda", que já naqueles idos era perceptível em toda a Europa:

A moda começa por ter isto de absurdo: é que não é ella que é feita para o corpo - é o corpo que tem de ser modificado para se ageitar

2 Doravante $\mathrm{F}$, nas referências de citações. Todas as citações foram retiradas da seguinte edição: ORTIGÃo, Ramalho; QUEIRÓS, Eça de. As farpas - chronica mensal da politica, das letras e dos costumes. Lisboa, Typographia Universal, mar. 1872. Disponível em: < http://purl. pt/256>. Acesso em: 20 jul. 2014.

3 Na revisão que fez de seus escritos d'As farpas para a obra Uma campanha alegre, Eça suprimiu e/ou reescreveu trechos dos textos. Portanto, com o intuito de revisão crítica, esclareço que no decorrer do trabalho utilizarei no corpo do artigo as citações originais e em nota de rodapé transcreverei os textos revistos, retirados de Uma campanha alegre; quando julgar necessário para os objetivos a que me proponho, farei comentários críticos relacionados à revisão textual operada pelo autor.

4 Doravante UCA nas referências de citações. Todas as citações foram retiradas da seguinte edição: QUEIRÓS, Eça de. Uma campanha alegre. Tomo I. São Paulo: Editora Brasiliense, 1961. 
n'ella. Ella vem de fora, pintada no figurino, feita à phantasia burgueza de um desenhador de armazem: e aqui, depois - é necessário reformar o corpo, obra do bom Deus - para o acommodar ao figurino, obra do jornal das damas: de modo que para sustentar o chapéo deforma-se a cabeça: para obedecer ao puff torce-se a espinha; para dar razão às botinas Luís XV desconjunta-se o pé; para seguir a altura das cintas destrói-se o busto. Nunca como hoje, sob o domínio da burguezia, se despresou, se deteriorou o corpo humano. (F, p. 52)

Em uma clara crítica ao culto da aparência em detrimento da valorização de outros aspectos, segundo Eça, mais importantes para a dignidade humana, a argumentação não poupa "farpas" à predileção burguesa pela aparência e pela indumentária que melhor caracterizasse e auferisse o status quo burguês. Um dos principais elementos, aliás, que Erich Hobsbawn elege para caracterizar a burguesia, é de fato a indumentária:

Precisamos olhar agora a sociedade burguesa. Os fenômenos mais superficiais são às vezes os mais profundos. Comecemos nossa análise desta sociedade, que atingiu seu apogeu neste período, pela aparência das roupas que seus membros usavam, pelos interiores que os cercavam. "As roupas fazem o homem", dizia um ditado alemão, e nenhuma época seguiu mais a risca tal idéia do que a época em que a mobilidade social poderia de fato colocar numerosas pessoas dentro de uma situação histórica inteiramente nova para desempenhar papéis sociais novos (e superiores), e portanto, tendo que usar as roupas apropriadas. (HOBSBAWN, 2012, p. 321)

É para os desdobramentos desse fenômeno na sociedade portuguesa que Eça, de maneira verborrágica e irônica, desenvolve a digressão.

5 "A moda começa por ter isto de absurdo: não é ela que é feita para o corpo - mas o corpo que tem de ser modificado para se ajeitar nela A moda vem de fora, do figurino, feita pela fantasia burguesa de um desenhador de armazém: e aqui, depois, a pobre mulher precisa de reformar o corpo, obra do seu bom Deus - para o acomodar ao figurino, obra do seu mau jornal. De modo que para sustentar o chapéu deforma-se a cabeça; para obedecer ao puff torce-se a espinha; para satisfazer às botinas Luís XV desconjunta-se o pé; para seguir o chique das cintas baixas destrói-se o busto. Nunca como hoje, sob o domínio da democracia, se desprezou, se deteriorou tanto o corpo humano." (UCA, p. 98, itálicos do autor, negrito meu). Note-se que além da atualização da grafia e da reconstrução de algumas sentenças, Eça faz uma alteração interessante no texto da década de 1890: ao invés de transcrever "sob o domínio da burguesia", ele propõe "sob o domínio da democracia", decisão que possivelmente expressa a maneira com que concebia a decadência burguesa nos anos 90 , ao mesmo tempo que explicitava as mudanças políticas, com a ascensão e a consolidação de regimes democráticos. Por outro lado, ao utilizar "sob o domínio da democracia" podemos também entender como se ele estivesse fazendo uso de sua típica fina ironia, pois, ao longo do texto, a tentativa é justamente a de propor que a sociedade daqueles idos vivia sob o autoritarismo de uma "ditadura da moda". 
Ele não descuida, inclusive, das ilusões que a maquiagem e os excessos dos apetrechos femininos poderiam causar sob a penumbra da luz do gás, enganando um apreciador mais desavisado, que poderia se espantar, à luz do dia, com a verdadeira face de uma distinta dama:

[As raparigas] Começam a precisar, para serem bonitas, da luz do gaz. Ahi sim: no brilho artificial d'aquella luz crua e opaca que põe em tudo um reflexo sem nuance, uma menina, com os cabellos lustrosos e os tulles espalhados, tem relevo e preciosidade. Mas que venha ao outro dia, a transparente, fina, intelligente luz do dia: então as fraquezas destacam: os cabelos chamuscados do ferro de frisar, estão seccos e côr de rato, a pele tem laivos rosados, os beiços são como um bago de romã expremida, o nariz tem na cartilagem que o liga ao rosto um vinco escuro, a boca encova... Ai Páris não lhe daria a maçã. (F, p. 52-53) ${ }^{6}$

A inquietação do escritor parece ser com um fenômeno de despersonalização e certo apagamento de individualidades, que não significava obviamente apagamento de classe social - mas que, ao contrário, atestava a necessidade de pertença e inserção social. Além disso, com os questionamentos voltados ao fato de que as mulheres eram subservientes, deixando-se levar pelos padrões impostos, sem terem ímpeto criativo, nota-se a indignação de Eça com um mundo já globalizado, no qual, nesse caso, os costumes parisienses impunham-se como indicadores de classe, regra a ser seguida para se ter distinção na sociedade, a despeito da desvalorização do que se verdadeiramente é, as singularidades individuais, além da perda de toda e qualquer originalidade:

[...] hoje mais que nunca se glorifica a beleza: o corpo é o fim, a lei, a conciencia. Sómente não se acceita o corpo que a natureza dá - e procura-se aquele que se vende nos armazens. [...] A moda destroe

6 “[As raparigas] Começam a precisar, para serem bonitas, da luz do gás. No brilho artificial daquela luz crua uma menina, com os cabelos lustrosos, um pouco de pó de arroz, e muitos tules espalhados, tem encanto e pode seduzir. Mas que venha, ao outro dia, a sincera luz da manhã! Todas as máculas destacam: os cabelos, chamuscados do ferro de frisar, estão secos e cor de rato, os beiços são como um velho bago de romã espremida, o nariz tem, na cartilagem que o liga ao rosto, um vinco escuro, toda a pele parece a de uma galinha cozida!..." (UCA, p. 98). Na revisão, Eça reescreve alguns trechos do texto e parece aproveitar para explicitar mais detalhes sobre os meios utilizados pelas moças para demonstrar uma beleza que não se tinha, especificando, principalmente, o uso da maquiagem para esconder as imperfeições do rosto. O aprofundamento crítico do texto revisto também se dá sobre a realidade que se queria esconder. Em Uma campanha alegre, a "verdadeira face", "à luz da manhã", merece muito mais que a não oferta da maçã por Páris, recebendo a descrição de "uma pele de galinha cozida". 
a belleza e destroe o espirito [...] um caixeiro desenha a lapis, em Paris, um certo corpete, umas certas mangas - e todas, magras e gordas, as loiras e as trigueiras, as ágeis, as debeis, as altas e as pequeninas, se introduzem, se alojam, se mettem n'aquelle molde, sem se preocuparem se o seu corpo, a sua côr de cabellos, o seu perfil, a sua altura, o seu peito, condizem, harmonisam, vão bem com o molde decretado e o molde vindo pelo correio. Abandonam-se servilmente ao figurino, abdicam a sua originalidade, o seu gosto, o seu engenho, o seu talento. Tornam-se imitadoras e copistas. Aceitam uma banalidade em seda e um logar commum com folhos. Agacham-se humilhadamente no gosto das ruas (F, p. 53- 54, itálico do autor $)^{7}$

A insistência da argumentação de Eça parece pairar, de fato, sobre a defesa de que a mulher, seduzida pelos modismos, perde a oportunidade de exercer a criatividade, a independência e a altivez da originalidade em criar suas próprias vestes:

\begin{abstract}
Uma senhora que não inventa, não cria os seus vestidos - é como um escriptor que não acha, não inventa as suas idéas. Ter a toilette do figurino, é fazer como os merceeiros que teem a opinião da sua gazeta. Deshabitua o espirito da invenção, da espontaneidade, da altiva liberdade. Torna a alma passiva, aceitando como um terreno esteril e neutro as idéas e as opiniões alheias. É uma confissão tacita de que se não tem espirito, nem phantasia. O figurino é a redução da originalidade a uma obediência a costureira: é servir a cabeça de um caixeiro diluida em prosa: é cumprir a Carta Constitucional dos pannos abretanhados, é seguir a elegância de cor, para ir recitar na rua; é a maneira barata de ter gosto de encommenda; é alugar o chic ao mez: é mandar vir as idéas pelo correio: é o bom tom por assignatura. Que falta de espirito! E os maridos pagam-n'o! (F, p. 54-55) ${ }^{8}$
\end{abstract}

7 "Hoje mais que nunca se glorifica a beleza, e o corpo é o fim supremo. Somente não se aceita o corpo que a natureza dá - e procura-se aquele que se vende nas modistas. (...) A moda destrói a beleza e destrói o espírito. Um caixeiro desenha a lápis, em Paris, um certo chapéu, um certo corpete, umas certas mangas - e todas, magras e gordas, as loiras e as trigueiras, as altas e as pequeninas, se introduzem, se alojam, se enfiam naquele molde, sem se preocuparem se o seu corpo, a sua cor, o seu perfil, a sua altura, o seu peito, condizem, harmonizam, vão bem com o molde decretado e chegado pelo correio. Abandonando-se servilmente ao figurino, abdicam a sua originalidade, o seu gosto. Aceitam uma banalidade em seda-e um lugar comum com folhos." (UCA, p. 98 - 99)

8 "Uma senhora que não inventa e não cria os seus vestidos - é como um escritor que não acha e não inventa as suas ideias. Ter a toilette do figurino, é fazer como os merceeiros que têm a opinião da sua gazeta. Desabitua o espírito da invenção, da espontaneidade, da liberdade. É uma confissão tácita de que se não tem espírito, nem fantasia. Seguir um figurino é aprender a elegância de cor, para a ir recitar na rua; é ter o gosto que se recebeu de encomenda; é alugar o chique, ao mês; é mandar vir as ideias pelo correio; é o bom tom por assinatura. Que falta de espírito! E os maridos pagam-no!" (UCA, p. 100). Entre as modulações de ordem ortográfica, percebe-se no texto de Uma 
A afirmação final de que "os maridos pagam", mais do que ser entendida como uma proposição machista, preconceituosa, constitui-se na totalidade do texto como uma espécie de alerta aos homens sobre as influências que a moda tinha na formação da mulher e que eles, em certa medida, não somente financiavam, mas eram sobretudo eram coniventes com isso.

Ao fim e ao cabo, as únicas apologias positivas dessa digressão fazem-se aos tempos antigos, nos quais "Uma larga túnica de linho, d'amplas pregas, que deixava o corpo livre, intacto, inopprimido, em toda a bella originalidade de suas linhas..." (F, p. 53) e "Um vestido inteiro, branco ou negro, modelando o corpo como uma luva, o pescoço livre, e os cabelos em duas tranças, ao comprido das costas!" (F, p. 53) ${ }^{10}$ eram suficientes para uma mulher se sentir plena.

A mesma perspicácia crítica "atemporal" de Eça, com relação à realidade, para a qual Eduardo Lourenço chama a atenção, pode ser percebida também em textos jornalísticos produzidos durante a última década de vida do escritor. Vejamos, como exemplo, o artigo crítico "Positivismo e idealismo" ${ }^{11}$, publicado em julho de 1893, na Gazeta de Notícias do Rio de Janeiro, e coligido no volume póstumo Notas contemporâneas, de 1909.

Durante a década de 1890, Eça de Queirós vivenciava na França o avanço do idealismo filosófico, corrente de pensamento que se opunha principalmente a uma das grandes teorias do século XIX, o positivismo. O escritor acompanhou com interesse o fenômeno antipositivista, demonstrando certa preocupação com relação à influência que o "neoidealismo", conforme ele mesmo denomina, poderia exercer não somente na filosofia, mas em todas as artes. Os embates entre as correntes de pensamentos foram expressos por Eça em artigos e crônicas, publicados em jornais e revistas da época ${ }^{12}$.

campanha alegre, a supressão de um considerável trecho d'As farpas, que retomo a seguir: "O figurino é a redução da originalidade a uma obediência a costureira: é servir a cabeça de um caixeiro diluída em prosa: é cumprir a Carta Constitucional dos pannos abretanhados". O escritor elimina da revisão as proposições que metaforicamente tentam explicar o que significava a subserviência aos padrões da moda. Metáforas que transpunham para outras situações, a manipulação de vários níveis sob a qual os seguidores dos padrões e dos modismos também estariam impostos. É impossível saber com certeza qual o motivo do texto ter sido ajustado nesse sentido, porém, além de supormos que Eça simplesmente julgou desnecessário desenvolver mais metáforas para aprofundar a ideia já explícita, poderíamos especular que o autor decidiu não aprofundar questões relacionadas às manipulações, especialmente no que se refere à política.

9 "Uma larga túnica de Linho, de amplas pregas, que deixava o corpo livre, inoprimido, em toda a bela originalidade das suas linhas..." (UCA, p. 99).

10 "Um vestido inteiro, branco ou negro, modelando o corpo como uma luva, o pescoço livre, os cabelos em duas tranças, ao comprido das costas" (UCA, p. 99).

11 Doravante PI, nas referências de citações.

12 Além do artigo "Positivismo e Idealismo", que analiso neste trabalho, refiro-me particularmente ao texto "O Bock Ideal", também publicado em 1893, no jornal Gazeta de Notícias do Rio de Janeiro. 
De acordo com Arnold Hauser, em seu já clássico História social da literatura e da arte (1973, p. 1048), mesmo havendo uma convivência de ideologias, as tendências idealistas e místicas estabeleceram-se como uma saída para o pessimismo vivenciado pela sociedade europeia, no contexto finissecular do Oitocentos, devido aos constantes avanços e transformações sociais que traziam agregados em si um crescente índice de desigualdade social.

Com isso, o Positivismo e o cientificismo começaram a ser desprezados, em parte, por conta do rápido desenvolvimento da técnica nas várias áreas do conhecimento, o qual não previa uma melhora na qualidade de vida dos cidadãos.

Alguns dos artigos e crônicas de Eça, escritos neste período, expõem justamente o paradoxo em que o progresso científico resultava, bem como as opiniões contrárias a ele, com uma avaliação que demonstra, por um lado, a valorização de algumas destas críticas, e, por outro, certa cautela com as ideias "neoidealistas" que começavam a surgir em oposição ao pensamento Positivista.

Há várias ressalvas feitas pelo próprio Eça com relação à nova corrente de pensamento que seduzia muitos na França, embora encontremos inegáveis críticas suas aos Positivistas e uma curiosidade frente ao renovado interesse idealista.

O artigo "Positivismo e idealismo" é valioso para percebermos o posicionamento de Eça frente a todas as mudanças que estavam ocorrendo no campo das ideias na França e, por conseguinte, para compreendermos a superação da maneira não romântica com que o escritor entendia as tensões presentes em diversas questões que se apresentavam diante de si, conforme defende Lourenço: "[...] a vivência do tempo que estrutura sua visão de mundo, aquela que a temporalidade romanesca encarnará de maneira inédita, releva da crítica e do naufrágio da ilusão romântica de um tempo ainda afectado de conteúdo transcendente." (LOURENÇO, 2006, p.36)

O artigo em questão é desenvolvido a partir das constatações de Eça acerca da intolerância e das lutas intelectuais e físicas entre estudantes neopositivistas e neoidealistas que agitavam Paris naqueles idos - mais propriamente a Universidade Sorbonne. As reflexões iniciam com o relato sobre a invasão da aula do professor Aulard ${ }^{13}$, positivista da Universidade

13 François Victor Alphonse Aulard (1849-1928), historiador e socialista radical, foi professor da Universidade Sorbonne, onde instituiu uma disciplina de estudos, voltada, especificamente, à discussão da Revolução Francesa. Era conhecido por difundir os métodos Positivistas em suas aulas, conferências e cursos. Demais informações sobre o intelectual podem ser encontradas no site da Enciclopédia Britannica: <http://www.britannica.com/EBchecked/topic/43172/Francois-Alphonse-Aulard >. Acesso em: 02 dez. 2013. 
Sorbonne, por parte de um grupo de estudantes idealistas, denominado "Mocidade das escolas". Aulard fazia apologia direta ao Positivismo em conferências e cursos ministrados no Bairro Latino e na Universidade, onde toda a celeuma acontecera.

A interrupção da aula de forma truculenta, "a berros e guinchos" (PI, p. 190), é o ponto de partida para Eça reconhecer que a causa da revolta estudantil dos neoidealistas se justificava de certa maneira, por conta do "modo brutal e rigoroso com que o positivismo científico tratou a imaginação, que é uma tão insuperável e legítima companheira do homem como a razão" (PI, p. 197):

O Positivismo científico, porém, considerou a imaginação como uma concubina comprometedora, de quem urgia separar o homem; e, apenas, se apossou dele, expulsou duramente a pobre e gentil imaginação, fechou o homem num laboratório a sós com sua esposa clara e fria, a razão. O resultado foi que o homem recomeçou a aborrecer-se monumentalmente e a suspirar por aquela outra companheira tão alegre, tão inventiva, tão cheia de graça e de luminosos ímpetos, que de longe se acenava ainda, lhe apontava para os céus da poesia e da metafísica, onde ambos tinham tentado vôos deslumbrantes. (PI, p. 197)

Tal justificativa não deixa de entrever, todavia, um Eça que se mostra apreensivo, juntamente com todos os denominados "bons espíritos" que já passavam dos cinquenta anos e esperavam que a nova geração "continuaria a revolução, só acreditaria na ciência e nos laboratórios e seria jacobina, positivista e naturalista" (PI, p. 196). Mas, ao contrário do que todos imaginavam, a juventude, "por meio de bengaladas energéticas, manifesta que sua tendência é espiritualista e simbolista, neocristã e místico-socialista” (PI, p. 197). Nas palavras do escritor:

$\mathrm{Eu}$, por mim, registro os fatos. E penso que, agora, que o homem tomou posse da sua ardente companheira, a imaginação, e que tornou a provar, francamente e coram populo, as delícias que só ela lhe pode dar, não consentirá, nestes anos mais chegados, que os seqüestrem dessa Circe adorável que transforma os seus amigos, não em porcos - mas em deuses (PI, p. 198).

É a partir deste ponto do artigo que Eça volve seu discurso para certo "movimento afirmativo de espiritualidade religiosa", que ele considera como resposta ao Positivismo e à forma com que os positivistas concebiam a imaginação. Tal fenômeno será tratado com receio porque poderia causar empecilhos ao livre pensar: 
Mas onde esta reação contra o positivismo científico se mostra mais decidida e franca é em matéria religiosa. Ah! o nosso velho e valente amigo, o livre pensamento vai atravessando realmente uma má crise! Talvez a mais aflitiva que ele tem afrontado, desde que nasceu sobre os claros céus helênicos e que balbuciou as suas primeiras lucubrações cósmicas e éticas, sobre os joelhos de Tales e de Sócrates [...]. Tudo isto é desolador. Tanto mais que, ao lado deste movimento negativo contra o Positivismo, surge e cresce paralelamente um movimento afirmativo de espiritualidade religiosa. (PI, p. 194-195).

Antes de continuar a crítica voltada ao "movimento de espiritualidade religiosa" Eça parece querer expor ainda as "ansiedades" que levavam os mais jovens a buscarem na Religião os desejos que a realidade "palpável" não poderia suprir:

É uma outra e renovada ansiedade de descobrir, neste complicado universo, alguma cousa mais do que força e matéria; de dar ao dever uma sanção mais alta, do que a que lhe fornece o código civil; de achar um princípio superior que promova e realize, no mundo, aquela fraternidade de corações e igualdade de bens, que nem o jacobinismo nem a economia política podem já realizar; e de achar, enfim, alguma garantia da prolongação da existência, sob qualquer forma, para além do túmulo. Esta é realmente a grande ansiedade, porque quanto mais a vida para cá do túmulo se alarga em atividade e se multiplica em força, mais profundamente se infiltra na alma a ânsia do não cessar ... Em suma, esta geração nova sente a necessidade do divino (PI, p. 195).

Parece que a "ânsia do não cessar" fará Eça reconhecer a necessidade de um pouco mais de idealismo no mundo materialista do positivismo, mas, concomitantemente, analisar com cautela a nova tendência idealista que cerceava o livre pensamento.

$\mathrm{Na}$ verdade, o que é perceptível, nas derradeiras linhas do artigo, é que a volta a um idealismo é visto com "bons olhos" desde que o processo não negue todas as conquistas sociais realizadas até aquele momento:

O estridente tumulto das cidades, a exageração da vida cerebral, a imensidade do esforço industrial, a brutalidade das democracias, hão de necessariamente levar muitos homens os mais sensíveis, os mais imaginativos, a procurar o refúgio do quietismo religioso - ou pelo menos a procurar no sonho um alívio à opressão da realidade. Mas esses mesmos não podem, nem destruir, nem sequer desertar o trabalho acumulado da civilização. (PI, p. 199) 
Não nos resta dúvida de que Eça demonstra uma desilusão com a austeridade, dureza e agitação desenvolvidas pelo Positivismo na vida moderna. Ele pode, inclusive, ser tido como um desses homens "sensíveis e imaginativos", basta lembrarmos da relação estreita entre os pensamentos materialistas e a vida estressante da urbe que será criticada em obras como "Civilização" (1892) e $A$ cidade e as serras (1901).

Por outro lado, não podemos deixar de lembrar o receio que ele manifesta ao longo de todo o texto com relação a uma total adesão ao idealismo.

É, por fim, nas últimas linhas do artigo que temos a síntese da forma com que o escritor analisa toda a mudança no pensamento moderno, principalmente no que diz respeito à convivência do pensamento positivista com o pensamento idealista:

Nunca mais ninguém, é certo, tendo fixo sobre si o olho rutilante e irônico da ciência, ousará acreditar que das feridas que o cilício abria sobre o corpo de S. Francisco, brotavam rosas de divina fragrância. Mas também, nunca mais ninguém, com medo da ciência, e das repreensões da fisiologia, duvidará em ir respirar, pela imaginação, e se for possível colher, as rosas brotadas do sangue do santo incomparável. E isto é para nós fazedores de prosa ou de verso, um positivo lucro e um grande alívio (PI, p. 200).

Essas linhas derradeiras do artigo são exemplares para notarmos o esforço do autor em tentar compreender a realidade que o cercava - realidade esta que estava em constante mudança. Elas comprovam que diversos temas veiculados em suas obras, na derradeira década de vida, não apontam para uma mudança total de perspectiva, como muitos críticos que leram a obra queirosiana propuseram.

É claro, todavia, que aspectos do Positivismo, do cientificismo, da industrialização, da modernidade, elogiados e ambicionados por todos os jovens da Geração de 70, mostravam para Eça de Queirós no final do século XIX outra face, aquela que provocava dor, miséria, desilusão, exclusão, desigualdade - enfim, inúmeros problemas sociais.

É por se dedicar tanto a questões como a dialética Positivismo versus Idealismo quanto a questões um tanto quanto prosaicas - porém, não menos perscrutadoras -, como a "ditadura da moda", que Eduardo Lourenço propõe o seguinte: "[...] uma das maiores originalidades de Eça foi tratar ou integrar as questões mais graves e candentes da sua época a propósito dos casos mais superficiais ou mundanos" (LOURENÇO, 2006, p. 39). Seria a argúcia em captar as transformações de seu tempo que imbuiria os textos de Eça da atemporalidade crítica. 
O que eu gostaria de propor, por fim, é que a leitura empreendida por Eduardo Lourenço em "O tempo de Eça e Eça e o tempo" é muito interessante não somente para reafirmarmos a atualidade da obra de Eça de Queirós para a contemporaneidade - ao considerar questões relacionadas à temporalidade narrativa, Eduardo Lourenço desloca a discussão sobre a produção de Eça do campo puramente estético, problematizando leituras críticas que por muitos anos vigoraram sobre a obra do escritor, e que quase sempre buscaram averiguar apenas o lugar ocupado pelos textos queirosianos no que se convencionou denominar de Realismo.

Com isso, há a possibilidade de questionar muitas propostas críticas que, por exemplo, ao lerem apressadamente a obra derradeira de Eça, propuseram-na ou como pouco detentora da "melhor" crítica realista empreendida em obras anteriores como $O$ crime do Padre Amaro (1875) e O primo Basílio (1880) ou como apaziguada com a sociedade portuguesa, caso de leituras menos acuradas das Vidas de santos (1981 - 1897?) e de A cidade e as serras.

De fato, conformismo não seria a palavra apropriada para classificar o posicionamento de Eça no final da vida com relação à Instituição religiosa e tudo o mais que é correlato a ela, como muitos críticos propuseram.

Lourenço principia seu texto afirmando: "Como sabemos, Eça de Queirós ainda entrou neste século" (LOURENÇO, 2006, p. 33) - referindo-se, na ocasião de sua fala, ao século XX. Quase 20 anos depois da proposição feita em "O tempo de Eça e Eça e o Tempo", podemos, no esteio de Eduardo Lourenço, reafirmar: "Eça entrou no século XXI e permanecerá". 


\section{REFERÊNCIAS}

BAUMAN, Zygmund. Modernidade Líquida. Rio de Janeiro: Jorge Zahar, 2001.

BERMAN, Marshall. Tudo que é sólido desmancha no ar - a aventura da modernidade. São Paulo: Companhia das Letras, 1998.

HAUSER, Arnold. História social da literatura e da arte. 3. ed. Tradução de Walter H. Geenen. Tomo II. São Paulo: Editora Mestre Jou, 1973.

HOBSBAWM, Eric J. A era do capital: 1848-1875. 2. ed. São Paulo: Paz e Terra, 2012. . A era dos Impérios: 1875-1914. 13. ed. São Paulo: Paz e Terra, 2011.

LOURENÇO, Eduardo. O tempo de Eça e Eça e o tempo. ENCONTRO INTERNACIONAL DE QUEIROSIANOS, 3., 1997, São Paulo. Anais... São Paulo: Centros de Estudos Portugueses da FFLCH da USP, 1997. p. 609-612.

. "O tempo de Eça e Eça e o tempo". Convergência Lusíada, nº 13. Rio de Janeiro, Real Gabinete Português de Leitura, 1996.

. O tempo de Eça e Eça e o tempo. In: . As saias de Elvira e outros ensaios. Lisboa: Gradiva, 2006.

ORTIGÃO, Ramalho; QUEIRÓS, Eça de. As farpas - chronica mensal da politica, das letras e dos costumes. Lisboa, Typographia Universal, mar. 1872. Disponível em: <http://purl.pt/256>. Acesso em: 20 jul. 2014.

QUEIRÓS, Eça de. Notas contemporâneas. Porto: Lello e Irmãos, 1945. Uma campanha alegre. Tomo I. São Paulo: Editora Brasiliense, 1961. . Uma campanha alegre. Tomo II. São Paulo: Editora Brasiliense, 1961.

Submetido em: 30/07/2014

Aceito em: 07/10/2014 